\title{
DWARFING ROOTSTOCKS FOR 'VALENCIA' SWEET ORANGE
}

\author{
Soares Filho, WS ${ }^{1}$, Ramos, $\mathrm{YC}^{2}$, Silva, $\mathrm{ALV}^{3}$, Fadel, $\mathrm{AL}^{2}$, Stuchi, $\mathrm{ES}^{1}$, Girardi, EA ${ }^{1}$, \\ Leão, $\mathrm{HC}^{3}$, Gesteira, $\mathrm{AS}^{1}$, Passos, $\mathrm{OS}^{1}$ \\ walter.soares@embrapa.br \\ ${ }^{1}$ Embrapa Cassava\&Fruits, Cruz das Almas, Brazil \\ ${ }^{2}$ Universidade de São Paulo, Piracicaba, Brazil \\ ${ }^{3}$ Citrosuco S/A Agroindústria, Matão, Brazil
}

The Brazilian citrus industry is requiring the use of rootstocks adapted for use in high planting densities with elevated production efficiency of high quality fruits, and tolerant/resistant to abiotic and biotic stresses. Hybrid rootstocks have been obtained by the Citrus Breeding Program of Embrapa Cassava \& Fruits, in Cruz das Almas, Bahia State, Brazil. Under rain-fed cultivation, the first four commercial crops of 'Valencia' sweet orange budded onto several rootstocks were evaluated in the municipal district of Colômbia, São Paulo State, Brazil (20 $10^{\prime} \mathrm{S}, 48^{\circ} 41^{\prime} \mathrm{W}, 492 \mathrm{~m}$ a. s. I.). Results indicated that the hybrids TSKC (Sunki mandarin) $\times$ [LCR (Rangpur lime) $\times$ TR (trifoliate orange)] - 001, - 017, - 059 and - 073, TSKC x CTSW (Swingle citrumelo) - 033 and - 041, LCR x TR - 001, LVK (Volkamer lemon) x LCR - 038 and HTR (trifoliate hybrid) - 051, - 053, - 069 and - 116 would allow planting densities higher than those attained with the use of vigorous rootstocks. They also induced higher production efficiency ( $\mathrm{kg}$ of fruits $/ \mathrm{m}^{3}$ of canopy) and fruits with greater or equivalent juice quality in relation to Rangpur lime, the usual rootstock in Brazil. Additionally, LCR $\times$ TR - 001, TSKC $\times$ CTSW - 041, TSKC $\times($ LCR $\times$ TR) -059 and LVK $\times$ LCR - 038 induced enhanced tolerance to drought and more precocious fruit bearing to 'Valencia' sweet orange with results similar to Rangpur lime. 